\title{
Appendiceal Carcinoid Pathologic Distant Metastasis TNM Finding v7
}

National Cancer Institute

\section{Source}

National Cancer Institute. Appendiceal Carcinoid Pathologic Distant Metastasis TNM

Finding v7. NCl Thesaurus. Code C89935.

A pathologic finding about one or more characteristics of appendiceal carcinoid, following the rules of the TNM AJCC V7 classification system as they pertain to distant metastases. There is no pathologic M0 for appendiceal carcinoid. (from AJCC 7th Ed.) 